\title{
Prognostic value of heart failure echocardiography index in HF patients with preserved, mid-ranged and reduced ejection fraction
}

\author{
Jian-Shu Chen ${ }^{1 \dagger}$, Ying Pei ${ }^{1 \dagger}$, Cai-e $\mathrm{Li}^{1}$, Ning-yin $\mathrm{Li}^{1}$, Tao Guo ${ }^{1}$ and Jing $\mathrm{Yu}^{1,2^{*}}$ (D)
}

\begin{abstract}
Background: To investigate the clinical value of heart failure echocardiography index (HFEl) in evaluating the cardiac function and predicting the prognosis of patients with different types of heart failure (HF).

Methods: Four hundred eighty-nine consecutively admitted HF patients were divided into three groups: HF with reduced ejection (HFrEF), HF with mid-range ejection fraction (HFmrEF), and HF with preserved ejection fraction (HFpEF). The baseline characteristics and ultrasound indexes were compared between the three groups. The correlation between HFEl and one-year risk of adverse events was compared by multivariate logistic regression. The clinical value of HFEl and plasma level of NT-proBNP in assessing the prognosis of patients with chronic heart failure (CHF) was analyzed by the receiver operating characteristic (ROC) curve.

Results: HFEl in HFrEF was significantly higher than that in HFmrEF and HFpEF. Multivariate regression analysis indicated that HFEl and plasma level of NT-proBNP were independent risk factors for predicting the short-time prognosis of HF patients. The ROC curve indicated that the HFEl cutoff level of 3.5 and the plasma NT-proBNP level of $3000 \mathrm{pg} / \mathrm{ml}$ predicted a poor prognosis of CHF patients with a sensitivity of $64 \%$ and a specificity of $75 \%$ vs. 68 and $65 \%$

Conclusion: HFEl can comprehensively evaluate the overall cardiac function of patients with various types of HF, and may prove to be an important index of assessing the prognosis of HF patients.
\end{abstract}

Keywords: Heart failure, Heart failure echocardiography index (HFEI), NT-proBNP, Prognosis

\section{Background}

Chronic heart failure (CHF) represents the final common pathway for the development and progression of most cardiovascular diseases and the leading cause of death $[1,2]$. Currently, the global prevalence of heart failure (HF) is about $2 \%$, with an annual incidence of $1 \%$

\footnotetext{
* Correspondence: 2072775154@qq.com

†Jian-shu Chen and Ying Pei had contributed equally to the manuscript. 'Lanzhou University Second College of Clinical Medicine, Number 199 Donggang West Road, Chengguan District, Lanzhou 730030, China 2Department of Cardiology, Second Hospital of Lanzhou University, No.82 Cui Ying Men, Cheng Guan District, Lanzhou 730030, China
}

[3]. In addition, with the global intensification of the aging process such as that in China, the number of HF patients continues to increase [4]. How to accurately diagnose and judge the prognosis in the early stage is the prerequisite and basis for effective treatment of HF patients.

Left ventricular ejection fraction (LVEF) and the left ventricular diastolic filling (LVDF) have long been used clinically to evaluate the LV systolic and diastolic functions respectively $[5,6]$. However, LVEF or LVDF alone is not closely related to the clinical condition and cannot

(c) The Author(s). 2020 Open Access This article is licensed under a Creative Commons Attribution 4.0 International License, which permits use, sharing, adaptation, distribution and reproduction in any medium or format, as long as you give appropriate credit to the original author(s) and the source, provide a link to the Creative Commons licence, and indicate if changes were made. The images or other third party material in this article are included in the article's Creative Commons licence, unless indicated otherwise in a credit line to the material. If material is not included in the article's Creative Commons licence and your intended use is not permitted by statutory regulation or exceeds the permitted use, you will need to obtain permission directly from the copyright holder. To view a copy of this licence, visit http://creativecommons.org/licenses/by/4.0/. The Creative Commons Public Domain Dedication waiver (http://creativecommons.org/publicdomain/zero/1.0/) applies to the data made available in this article, unless otherwise stated in a credit line to the data. 
accurately reflect the overall cardiac function of HF patients. The HF echocardiography index (HFEI) is a combination of multiple parameters of echocardiography to evaluate the cardiac function in patients with CHF, which overcomes the subjective factors of New York Heart Association Classification and is more accurate and reliable than the single LVEF $[7,8]$.

The 2016 European Society of Cardiology (ESC) has updated its guidelines for HF. In addition to retaining HF with reduced ejection (HFrEF) and HF with preserved ejection fraction (HFpEF), a new type named HF with mid-range ejection fraction (HFmrEF) has been added [9]. Our study aims to investigate the value of HFEI in evaluating the cardiac function in patients with different types of $\mathrm{HF}$ and the clinical predictive value of HFEI for the prognosis of patients with CHF.

\section{Methods}

\section{Study population}

This study included 489 HF patients who were admitted to the Department of Cardiovascular Medicine of the Affiliated Hospital of Lanzhou University (Lanzhou, China) between January 2016 and December 2018. They included 268 males and 221 females, with a mean age of $64 \pm 14$ years. Inclusion criteria were as follows: (1) the diagnosis of heart failure is confirmed by two or more experienced cardiologists according to the 2016 ESC guidelines;(2) we can collect comprehensive clinical data; and (3) the one-year follow-up data of the patients were complete. The exclusion criteria were as follows: (1) patients with kidney disease, liver disease or severe liver and kidney dysfunction;(2) tumor, nervous system disease; All patients signed the informed consent forms before enrollment.

\section{Clinical data collection}

The demographic characteristics and comorbidities of the patients were obtained on admission. All hematological specimens including blood routine, blood biochemistry or NT-proBNP were collected within $24 \mathrm{~h}$ after admission and tested in the central laboratory of the hospital. All clinical data were recorded by one physician and reviewed by another.

\section{Echocardiography}

The GE Vivid 7 ultrasound system was used, with a probe frequency of $3.4-5.0 \mathrm{mHz}$. The measurement was performed by the same professional physician using the means of the results obtained from three consecutive cardiac cycles. Measurement indicators included: (1) the cardiac structure: LVEF, LV end diastolic diameter (LVEDD), interventricular septal thickness (IVST), LV posterior wall thickness (LVPWT), left atrial volume index (LAVi), diameter of left atrium (LAD) calculate relative ventricular wall thickness $($ RVWT $)=2 \times$ LVPW $\mathrm{Td} / \mathrm{LVEDD}$, and LV mass index (LVMi) $=\mathrm{LVM} /$ body surface area; (2) cardiac function: peak velocity during early filing(E), late filling from atrial contraction (A), E/ A ratio, left ventricular early diastolic flow propagation velocity (FPV), E/FPV, peak systolic mitral annular velocity $\left(\mathrm{S}^{\prime}\right), \mathrm{E} / \mathrm{E}$ 'S ratio, pulmonary arterial systolic pressure (PASP), early diastolic mitral flow deceleration time (DT), pulmonary venous flow (S peak systolic wave velocity and $\mathrm{D}$ peak diastolic wave velocity), and $\mathrm{D} / \mathrm{S}$ ratio.

\section{HFEI}

According to the related indexes of echocardiography, the total score was HFEI. The HFEI scoring criteria are as follows: (1) $35 \leq \mathrm{PASP}<50 \mathrm{mmHg}, 1$ point, $\mathrm{PASP} \geq 50$ mmHg, 2 point; (2) LV systolic function: $30 \% \leq \mathrm{LVEF}<$ $45 \%$ or regional ventricular wall motion abnormality, 1 point, $\mathrm{LVEF}<30 \%, 2$ point; (3) $\mathrm{LV}$ diastolic function: (1) $\mathrm{E} / \mathrm{A}<0.5, \mathrm{DT}>220 \mathrm{~ms}, \mathrm{D} / \mathrm{S}<1$ or $\mathrm{E} / \mathrm{A}=1-2, \mathrm{DT}=$ $150-220 \mathrm{~ms}, \mathrm{D} / \mathrm{S} \geq 1,1$ point; (2) $/ \mathrm{A}>2$, DT $<150 \mathrm{~ms}$, D/ $\mathrm{S}>1$ or restrictive change, 2 point; (4) atrioventricular remodeling: (1) $56 \mathrm{~mm}<\mathrm{LVEDD}<66 \mathrm{~mm}$, IVST or LVPWT $\geq 13 \mathrm{~mm}, \mathrm{LAD} \geq 45 \mathrm{~mm}, 1$ point; (2LVEDD $\geq 66$ mm or right ventricular dysfunction; (5) valvular regurgitation or valvular stenosis: moderate, 1 point, serious, 2 point (Table 1) [10, 11].

\section{Follow-up evaluation and study end points}

All patients were followed up on the outpatient basis, telephone interviews and readmission medical records, with a mean follow-up period of 1 year. End-point events observed in the study were all-cause death, cardiovascular death and hospitalization for $\mathrm{HF}$ exacerbation.

\section{Statistical analysis}

All data were analyzed using SPSS 21.0 statistical software. Mean \pm standard deviation (SD) was used for continuous variables which accord with the normal distribution and the homogeneity test of variance. The three groups of data were compared by the ANOVA test. Categorical variables were expressed as percentage and analyzed by the chi-square test. Univariate and multivariate logistic regression models were used to analyze the correlation between HFEI and the risk of one-year adverse events. The ROC curve was performed to evaluate the diagnostic performance of HFEI and NTproBNP in patients with poor prognosis. A $p$ value < 0.05 was pre-specified to indicate statistical significance.

\section{Results}

\section{Comparison of the baseline characteristics}

Four hundred and eighty-nine patients with HF were recruited and divided into three groups, including 170 in 
Table 1 Heart failure echocardiography index score criteria

\begin{tabular}{|c|c|c|}
\hline & Indicators & Score \\
\hline \multirow[t]{2}{*}{ Left ventricular systolic function } & $30 \% \leq \mathrm{LVEF}<45 \%$ or regional ventricular wall motion abnormality & 1 point \\
\hline & LVEF $<30 \%$ & 2 point \\
\hline \multirow[t]{2}{*}{ Left ventricular diastolic function } & $\mathrm{E} / \mathrm{A}<0.5, \mathrm{DT}>220 \mathrm{~ms}, \mathrm{D} / \mathrm{S}<1$ or $\mathrm{E} / \mathrm{A}=1-2, \mathrm{DT}=150-220 \mathrm{~ms}, \mathrm{D} / \mathrm{S} \geq 1$ & 1 poi \\
\hline & $\mathrm{E} / \mathrm{A}>2, \mathrm{DT}<150 \mathrm{~ms}, \mathrm{D} / \mathrm{S}>1$ or restrictive change & 2 poi \\
\hline \multirow[t]{2}{*}{ Pulmonary arterial systolic pressure } & $35 \leq \mathrm{PASP}<50 \mathrm{mmHg}$ & 1 point \\
\hline & $\mathrm{PASP} \geq 50 \mathrm{mmHg}$ & 2 point \\
\hline \multirow[t]{2}{*}{ Atrioventricular remodeling } & $56 \mathrm{~mm}<$ LVEDD $<66 \mathrm{~mm}$, IVST or LVPWT $\geq 13 \mathrm{~mm}, \mathrm{LAD} \geq 45 \mathrm{~mm}$ & 1 point \\
\hline & LVEDD $\geq 66 \mathrm{~mm}$ or right ventricular dysfunction & 2 point \\
\hline \multirow[t]{2}{*}{ Valvular regurgitation or valvular stenosis } & moderate & 1 point \\
\hline & serious & 2 poi \\
\hline
\end{tabular}

$D T$ early diastolic mitral flow deceleration time, $D / S$ pulmonary venous flow (S peak systolic wave velocity and $D$ peak diastolic wave velocity), E/A peak velocity during early filing(E), late filling from atrial contraction (A), IVST interventricular septal thickness, LVEF left ventricular ejection fraction, LVEDD left ventricular end diastolic diameter, PASP pulmonary arterial systolic pressure, LVPWT left ventricular posterior wall thickness

HFrEF, 171 in HFmrEF and 148 in HFpEF. There were no significant differences in age, diastolic blood pressure (DBP), blood urea nitrogen (BUN) and $\alpha$ hydroxybutyrate dehydrogenase $(\alpha-\mathrm{HBDH})$ between the three groups of HF patients, while there were significant differences in HFEI and NT-proBNP between the three groups. The characteristics of the included patients are summarized in Table 2.

\section{Comparison of the echocardiographic indexes}

Analysis of the echocardiographic parameters in the three groups of patients showed that there were significant differences in the indicators that reflect the ventricular structure including LVEDD, LAD, LVMI and RWT, and in the indicators that reflect the ventricular function including E/FPV and E/E'S. No variances were found in the remaining indicators (Table 3).

\section{Logistic regression analysis}

Multiple logistic regression analysis was performed on variables that may affect the adverse prognosis of HF patients. It was found that NT-proBNP and HFEI were related to the risk of one-year adverse events. However, there was no correlation between LAVi, LVMi, $\alpha-\mathrm{HBDH}$ and endpoint events (Table 4).

\section{The value of HFEI and NT-proBNP in predicting the one-} year risk of adverse events in HF patients

The sensitivity and specificity of NT-proBNP and HFEI to predict the risk of one-year adverse events in patients with HF were analyzed by plotting the ROC curve, and the Jordon index was calculated. When NT-proBNP was $3000 \mathrm{pg} / \mathrm{ml}$, the area under the ROC curve was 0.698 (sensitivity $68 \%$, specificity $65 \%$ ). The greatest area under the ROC curve of HFEI was 0.712 , and the optimal cut-off value was 3.5 (sensitivity $64 \%$, specificity $78 \%$ ) (Fig. 1). According to the cutoff value of HFEI and NT-
proBNP, HF patients were divided into the following four groups: group A: $\mathrm{HFEI}<3.5$ and $\mathrm{NT}$-proBNP $<3000$ $\mathrm{pg} / \mathrm{ml}$; group B: $\mathrm{HFEI}<3.5$ and NT-proBNP $>3000 \mathrm{pg} / \mathrm{ml}$; group C: $\mathrm{HFEI}>3.5$ and $\mathrm{NT}-\mathrm{proBNP}<3000 \mathrm{pg} / \mathrm{ml}$; group D: HFEI $>3.5$ and NT-proBNP>3000 pg/ml. The one-year risk of adverse events in HF patients between groups was analyzed using Partitions of $\chi^{2}$ method. The incidence of one-year adverse events in group A was lower than that in group C and D. Group D had a higher incidence of one-year adverse events than group $D$ (Table 5).

\section{Discussion}

This observational study yielded the following results: (1) there were significant differences in HFEI between HFrEF, HFmrEF and HFpEF patients; (2) multivariate regression analysis indicated that HFEI and NT-proBNP were independent risk factors for the prognosis of oneyear adverse events in HF patients; and (3) HFEI and NT-proBNP had a good value in predicting the shortterm prognosis of $\mathrm{HF}$ patients.

Clinically, LVEF and LV filling indicators are generally used to evaluate the cardiac function in HF patients, but single indexes cannot reflect the overall cardiac function, especially in patients with HFpEF and HFrEF, in whom LVEF does not always reflect the severity of HF. HFEI is a comprehensive ultrasound index for evaluating the cardiac function by taking into full account the changes in LV systolic and diastolic function, valve regurgitation and atrioventricular remodeling [12, 13]. In addition, HFEI is not affected by the heart rate and ventricular geometry, and is highly correlated with the LV function indicators measured by cardiac catheterization, which can fully reflect the overall function of the heart. As the the present study has demonstrated significant differences in HFEI between the three types of HF patients, the evaluation of patients could be conducted objectively 
Table 2 Baseline characteristics of the study population

\begin{tabular}{|c|c|c|c|c|}
\hline & $\begin{array}{l}\text { HFrEF } \\
(n=170)\end{array}$ & $\begin{array}{l}\text { HFmrEF } \\
(n=171)\end{array}$ & $\begin{array}{l}\text { HFpEF } \\
(n=148)\end{array}$ & $p$ value \\
\hline Age (years) & $62.20 \pm 14.82$ & $64.22 \pm 13.18$ & $67.02 \pm 13.22$ & $0.008^{*}$ \\
\hline Male, n(\%) & $98(57)$ & $93(54)$ & $79(53)$ & 0.758 \\
\hline BMI (kg/m2) & $25.25 \pm 15.10$ & $25.76 \pm 16.53$ & $25.36 \pm 14.57$ & 0.575 \\
\hline WHR & $0.93 \pm 0.06$ & $0.92 \pm 0.06$ & $0.92 \pm 0.08$ & 0.575 \\
\hline $\mathrm{SBP}(\mathrm{mmHg})$ & $\begin{array}{l}135.19 \pm \\
20.86\end{array}$ & $\begin{array}{l}137.80 \pm \\
25.71\end{array}$ & $\begin{array}{l}137.42 \pm \\
28.40\end{array}$ & 0.597 \\
\hline $\mathrm{DBP}(\mathrm{mmHg})$ & $77.83 \pm 12.36$ & $80.64 \pm 16.19$ & $82.06 \pm 16.14$ & $0.043^{*}$ \\
\hline HR (beats/min) & $78.75 \pm 13.83$ & $81.17 \pm 16.02$ & $78.88 \pm 15.40$ & 0.264 \\
\hline WBC(10^9/L) & $6.35 \pm 1.86$ & $6.44 \pm 1.85$ & $6.42 \pm 2.73$ & 0.942 \\
\hline $\mathrm{RBC}(10 \wedge 12 / L)$ & $4.68 \pm 0.65$ & $4.49 \pm 0.68$ & $4.56 \pm 0.74$ & 0.065 \\
\hline $\begin{array}{l}\text { Hemoglobin } \\
(\mu \mathrm{mol} / \mathrm{L})\end{array}$ & $\begin{array}{l}143.83 \pm \\
19.44\end{array}$ & $\begin{array}{l}136.38 \pm \\
20.17\end{array}$ & $\begin{array}{l}138.58 \pm \\
22.74\end{array}$ & 0.530 \\
\hline $\mathrm{HCT}$ & $0.40 \pm 0.09$ & $0.41 \pm 0.35$ & $0.41 \pm 0.08$ & 0.821 \\
\hline $\mathrm{ALT}(\mathrm{U} / \mathrm{L})$ & $42.19 \pm 56.06$ & $34.44 \pm 41.43$ & $27.73 \pm 22.84$ & 0.120 \\
\hline $\mathrm{AST}(\mathrm{U} / \mathrm{L})$ & $33.91 \pm 43.34$ & $29.01 \pm 20.40$ & $25.92 \pm 13.25$ & 0.052 \\
\hline BUN (mmol/L) & $8.15 \pm 8.62$ & $6.88 \pm 2.93$ & $6.69 \pm 3.05$ & $0.039^{*}$ \\
\hline $\mathrm{CR}(\mu \mathrm{mol} / \mathrm{L})$ & $91.47 \pm 31.72$ & $91.13 \pm 38.32$ & $86.54 \pm 36.71$ & 0.407 \\
\hline $\mathrm{TC}(\mathrm{mmol} / \mathrm{L})$ & $3.89 \pm 1.06$ & $3.82 \pm 0.95$ & $3.75 \pm 1.08$ & 0.512 \\
\hline $\mathrm{HDL}-\mathrm{C}(\mathrm{mmol} / \mathrm{L})$ & $1.14 \pm 0.33$ & $1.15 \pm 0.30$ & $1.13 \pm 0.33$ & 0.881 \\
\hline LDL-C (mmol/L) & $4.42 \pm 2.62$ & $2.26 \pm 0.88$ & $2.15 \pm 0.89$ & 0.401 \\
\hline UA $(\mu \mathrm{mol} / \mathrm{L})$ & $\begin{array}{l}394.90 \pm \\
132.62\end{array}$ & $\begin{array}{l}381.57 \pm \\
130.29\end{array}$ & $\begin{array}{l}364.08 \pm \\
117.24\end{array}$ & 0.105 \\
\hline $\mathrm{LDH}(\mathrm{U} / \mathrm{L})$ & $\begin{array}{l}209.76 \pm \\
78.75\end{array}$ & $\begin{array}{l}224.31 \pm \\
100.24\end{array}$ & $\begin{array}{l}209.18 \pm \\
79.71\end{array}$ & 0.330 \\
\hline $\mathrm{a}-\mathrm{HBDH}(\mathrm{U} / \mathrm{L})$ & $\begin{array}{l}428.09 \pm \\
263.19\end{array}$ & $\begin{array}{l}243.54 \pm \\
163.23\end{array}$ & $\begin{array}{l}298.20 \pm \\
160.83\end{array}$ & $0.015^{*}$ \\
\hline $\mathrm{HCY}(\mu \mathrm{mol} / \mathrm{L})$ & $20.79 \pm 9.55$ & $28.67 \pm 38.31$ & $26.07 \pm 16.04$ & 0.772 \\
\hline $\begin{array}{l}\text { NT-proBNP (pg/ } \\
\mathrm{ml})\end{array}$ & $\begin{array}{l}6835.52 \pm \\
6456.96\end{array}$ & $\begin{array}{l}3628.96 \pm \\
4997.18\end{array}$ & $\begin{array}{l}1309.34 \pm \\
1125.50\end{array}$ & $0.000^{*}$ \\
\hline $\begin{array}{l}\text { Hypertension, } \\
\text { n(\%) }\end{array}$ & $65(38)$ & $89(52)$ & $86(58)$ & $0.006^{*}$ \\
\hline Diabetes,n(\%) & 33(19) & $25(15)$ & $38(26)$ & 0.130 \\
\hline $\begin{array}{l}\text { Atrial fibrillation, } \\
\mathrm{n}(\%)\end{array}$ & $15(9)$ & $22(13)$ & $21(14)$ & 0.447 \\
\hline
\end{tabular}

ALT alanine transaminase, AST aspartate aminotransferase, $a-H B D H$ ahydroxybutyrate dehydrogenase, $B U N$ blood urea nitrogen, $B M I$ body mass index, $C R$ creatinine, DBP diastolic blood pressure, $H C T$ hematocrit, $H R$ heart rate, $H C Y$ homocysteine, $H D L-C$ high-density lipoprotein cholesterol, $L D H$ lactate dehydrogenase, $L D L-C$ low-density lipoprotein cholesterol, $R B C$ red blood cell, SBP systolic blood pressure, TC total cholesterol, UA uric acid, WHR waist hip ratio, $W B C$ white blood cell

${ }^{*} p<0.05$ indicates a statistically significant differences among HFrEF, HFmrEF and HFpEF

through the comprehensive echocardiographic parameters.

NT-proBNP is a cardiac neurohormone secreted by the ventricles, playing an important role in the diagnosis and prognosis of HF $[14,15]$. However, studies have shown that plasma NT-proBNP level in patients with chronic kidney disease and cor pulmonale are also
Table 3 Echocardiographic indexes of the study population

\begin{tabular}{|c|c|c|c|c|}
\hline & $\operatorname{HFrEF}(n=170)$ & $\begin{array}{l}\text { HFmrEF } \\
(n=171)\end{array}$ & $\operatorname{HFpEF}(n=148)$ & $p$ value \\
\hline /EF & $30.78 \pm 5.34$ & $44.24 \pm 3.87$ & 61.45 & 0.000 \\
\hline$A$ & $26+071$ & $1.14 \pm 0.90$ & $1.06 \pm 0.81$ & 0.389 \\
\hline s) & 7. & 7.88 & 3 & 0.927 \\
\hline$E^{\prime} L$ & 12 & $12.48 \pm 4.87$ & 11.7 & 0.396 \\
\hline$(\mathrm{cm} / \mathrm{s})$ & 4. & $5.56 \pm$ & 5.7 & 0.088 \\
\hline E'E'S & $19.38 \pm 11.27$ & $17.15 \pm 7.48$ & $14.94=$ & $0.037^{*}$ \\
\hline $\mathrm{T}(\mathrm{ms})$ & 182.0 & 207. & 12 & 0.062 \\
\hline d/S & $1.37 \pm 0.87$ & $1.49 \pm 0.59$ & $1.28 \pm 0.43$ & $0.019^{*}$ \\
\hline /EDD ( $\mathrm{r}$ & $65.52 \pm$ & $58.23 \pm 15.94$ & 48.2 & $0.000^{*}$ \\
\hline $\mathrm{AD}(\mathrm{mm})$ & $46.96 \pm 11.04$ & $44.09 \pm 13.72$ & $38.18 \pm 9.29$ & $0.000^{*}$ \\
\hline (1) & $8.68 \pm 2.20$ & $8.92 \pm 2.35$ & $8.88=$ & 0.062 \\
\hline WT (mm) & $9.15 \pm 2.38$ & $9.19 \pm 2.14$ & $9.71 \pm 2.08$ & 0.069 \\
\hline WT (mm) & $0.31 \pm 0.08$ & $0.42 \pm 0.11$ & $0.44 \pm 0.11$ & $0.000^{*}$ \\
\hline LVEDV (ml) & $181.81 \pm 63.51$ & $119.32 \pm 59.76$ & $94.80 \pm 38.02$ & $0.000^{*}$ \\
\hline /ESV (ml) & $120.12 \pm 48.22$ & $53.77 \pm 40.87$ & $37.24 \pm 18.72$ & $0.000^{*}$ \\
\hline LAVi & $58.76 \pm 7.58$ & $50.59 \pm 29.34$ & $49.12 \pm 18.15$ & 0.135 \\
\hline VRT (ms) & $86.26 \pm 28.45$ & $87.46 \pm 32.74$ & $77.62 \pm 23.93$ & 0.093 \\
\hline Tei & 0.6 & 0.68 & 0 & 0. \\
\hline $\mathrm{FPV}(\mathrm{cm} / \mathrm{s})$ & $34.19 \pm 13.01$ & $45.33 \pm 19.36$ & $51.61 \pm 21.44$ & $0.000^{*}$ \\
\hline $\mathrm{v}$ & 2. & 0.83 & 57 & $0.000^{*}$ \\
\hline LVMi & $167.43 \pm 43.59$ & $133.61 \pm 37.51$ & $115.49 \pm 31.98$ & $0.000^{*}$ \\
\hline El & $5.54 \pm 1.20$ & $4.12 \pm 1.52$ & $2.45 \pm 1.16$ & $0.001^{*}$ \\
\hline
\end{tabular}

$D T$ early diastolic mitral flow deceleration time, $D / S$ pulmonary venous flow $(S$ peak systolic wave velocity and $D$ peak diastolic wave velocity), $E^{\prime} L$ maximum velocity in early diastole of mitral annulus- lateral wall, $E^{\prime} S$ maximum velocity in early diastole of mitral annulus- interventricular septum, E/A peak velocity during early filing(E), late filling from atrial contraction (A), FPV left ventricular early diastolic flow propagation velocity, HFEI heart failure echocardiography index, IVRT isovolumic relaxation time, IVST interventricular septal thickness, LVEDV left ventricular end diastolic volume, LVESV left ventricular end systolic volume, $L A D$ diameter of left atrium, $L A V i$ left atrial volume index, $L V M i$ left ventricular mass index, LVEDD left ventricular end diastolic diameter, LVEF left ventricular ejection fraction, PWT posterior wall thickness, RWT relative wall thickness

${ }^{*} p<0.05$ indicates a statistically significant differences among $\mathrm{HFrEF}, \mathrm{HFmrEF}$ and HFpEF

Table 4 Logistic regression analysis of one-year adverse event risk in patients with heart failure

\begin{tabular}{llll}
\hline Index & OR & $95 \% \mathrm{Cl}$ & $p$ value \\
\hline Age & 1.021 & $0.993-1.049$ & 0.512 \\
LAD & 0.919 & $0.831-1.016$ & 0.100 \\
LVMi & 1.002 & $0.986-1.081$ & 0.759 \\
a-HBDH(U/L) & 1.001 & $0.999-1.004$ & 0.282 \\
HFEl & 1.263 & $1.040-1.533$ & 0.019 \\
NT-proBNP $(\mathrm{pg} / \mathrm{ml})$ & 1.000 & $0.966-1.025$ & 0.010 \\
\hline
\end{tabular}

$a-H B D H$ a-hydroxybutyrate dehydrogenase, $\mathrm{Cl}$ confidence intervals, HFEl heart failure echocardiography index, $L A D$ left atrial volume index, $L V M i$ left ventricular mass index

${ }^{*} p<0.05$ indicates a statistically significant differences 


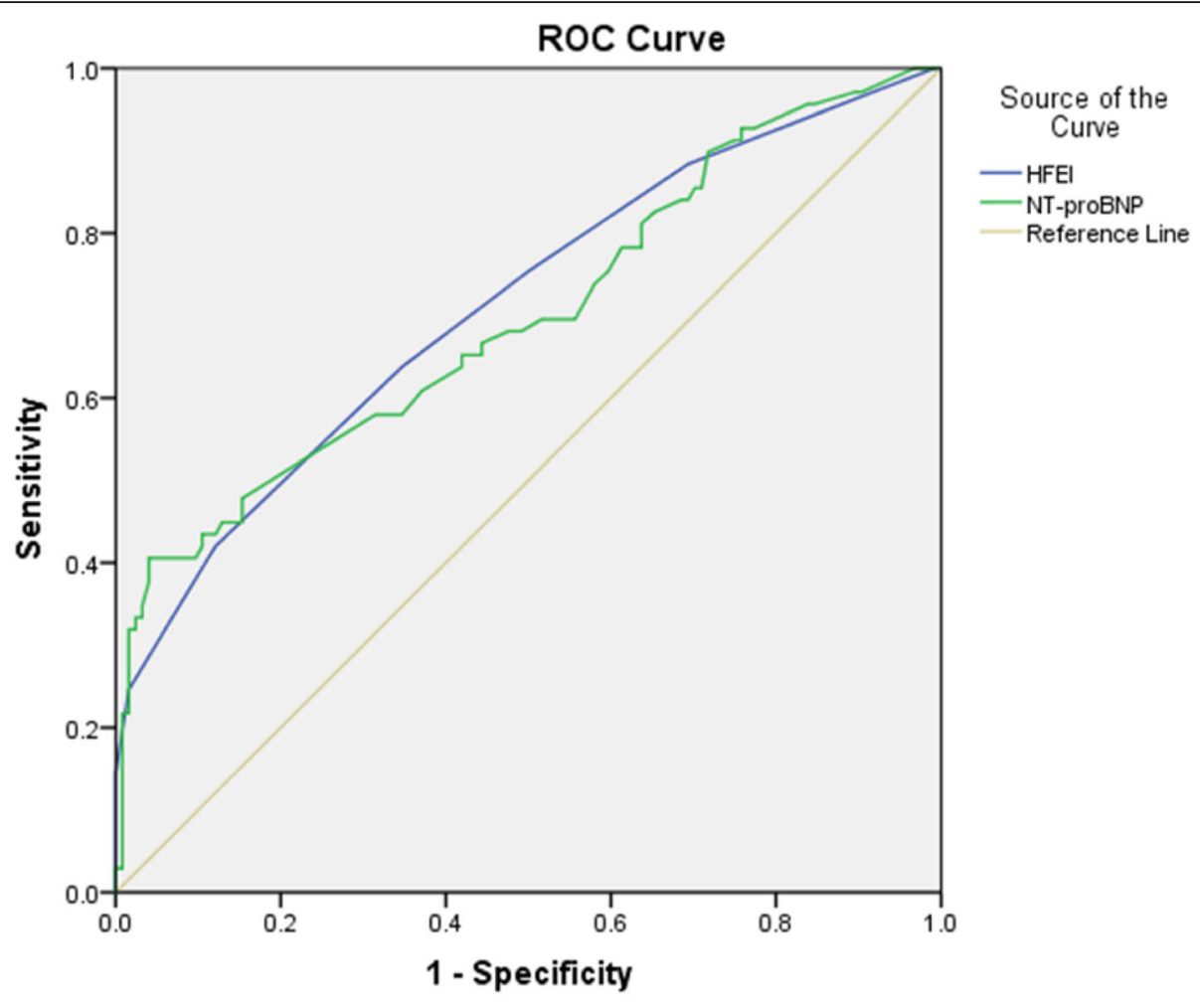

Diagonal segments are produced by ties.

Fig. 1 Receiver operating characteristic (ROC) curves of heart failure echocardiography index (HFEl) and NT-proBNP for predicting adverse events within 1 year in patients with heart failure. The maximum area under the ROC curve of heart failure echocardiography index and NT-proBNP was 0.712 and 0.698 , respectively

Table 5 Partitions of $x 2$ method analysis of one-year adverse event risk in patients with heart failure

\begin{tabular}{|c|c|c|c|c|c|}
\hline \multirow[t]{2}{*}{ Group } & \multicolumn{2}{|c|}{ One-year adverse events } & \multirow[t]{2}{*}{ All } & \multirow[t]{2}{*}{$x^{2}$} & \multirow[t]{2}{*}{$p$} \\
\hline & yes & no & & & \\
\hline $\bar{A}$ & 10 & 136 & 146 & 1.25 & $0.263>0.0083$ \\
\hline B & 11 & 90 & 101 & & \\
\hline A & 10 & 136 & 146 & 9.21 & $0.002<0.0083^{*}$ \\
\hline C & 18 & 72 & 90 & & \\
\hline A & 10 & 136 & 146 & 18.16 & $0.000<0.0083^{*}$ \\
\hline D & 38 & 114 & 152 & & \\
\hline B & 11 & 90 & 101 & 3.07 & $0.080>0.0083$ \\
\hline C & 18 & 72 & 90 & & \\
\hline B & 11 & 90 & 101 & 7.74 & $0.005<0.0083^{*}$ \\
\hline D & 38 & 114 & 152 & & \\
\hline C & 18 & 72 & 90 & 0.8 & $0.373>0.0083$ \\
\hline$D$ & 38 & 114 & 152 & & \\
\hline
\end{tabular}

A: HFEl<3.5 and NT-proBNP<3000 pg/ml; B: HFEl<3.5 and NT-proBNP $>3000 \mathrm{pg} / \mathrm{ml}$

C: HFEl $>3.5$ and NT-proBNP<3000 pg/ml; D: HFEl $>3.5$ and NT-proBNP $>3000 \mathrm{pg} / \mathrm{ml}$

${ }^{*} p<0.0083$ indicates a statistically significant differences significantly increased, so NT-proBNP is not the specific diagnostic criterion for HF [16]. Several studies have shown a correlation between the multiple echocardiographic evaluation indicators (E/A and LVEF) included in HFEI and plasma NT-proBNP levels $[8,17]$. Chen et al. suggested that HFEI could judge the degree of HF in HFmrEF patients and had a good correlation with NT-proBNP [18]. In this study, all the HF patients were followed up for 1 year to record the occurrence of adverse events and evaluate the prognosis. The result of multivariate logistic regression analysis also showed a significant correlation between NT-proBNP and shortterm prognosis of HF patients. We also compared the value of HFEI and NT-proBNP in assessing short-term outcomes in HF patients. By plotting the ROC curve, it was found that the area under the curve for HFEI and NT-proBNP differed by 0.712 and 0.698 , respectively. Therefore, NT-proBNP alone may not be sufficient to predict the risk of one-year adverse events in HF patients. Combination of a high plasma level of NTproBNP and HFEI may improve the accuracy of prognostic prediction.

There are some shortcomings in this study. On the one hand, the study population was from a single center 
with a smaller sample size. On the other hand, the follow-up period was relatively short. Therefore, more studies with larger sample sizes and longer follow-up time are required to fully demonstrate the value of HFEI in the diagnosis and prognostic prediction of $\mathrm{HF}$ patients.

\section{Conclusion}

In summary, the preliminary data obtained in this study suggest that HFEI could objectively predict the prognosis of patients with HF. HFEI and plasma NT-proBNP level are well correlated with the risk of adverse events, and combination of the two can improve the accuracy of prediction.

\section{Abbreviations}

CHF: Chronic heart failure; HF: Heart failure; LVEF: Left ventricular ejection fraction; LVDF: The left ventricular diastolic filling; HFEl: Heart failure echocardiography index; ESC: European society of cardiology; HFrEF: Heart failure with reduced ejection; HFpEF: Heart failure with preserved ejection fraction; HFmrEF: Heart failure with mid-range ejection fraction; LVEDD: Left ventricular end diastolic diameter; IVST: Interventricular septal thickness; LVPWT: Left ventricular posterior wall thickness; LAVi: Left atrial volume index; RWWT: Calculate relative ventricular wall thickness; index; E: Peak velocity during early filing; A: Late filling from atrial contraction; FPV: Left ventricular early diastolic flow propagation velocity; $S^{\prime}$ : Peak systolic mitral annular velocity; PASP: Pulmonary arterial systolic pressure; DT: Early diastolic mitral flow deceleration time; DBP: Diastolic blood pressure; BUN: Blood urea nitrogen; a-HBDH: a-Hydroxybutyrate dehydrogenase

\section{Acknowledgements}

The authors would like to thank Dr. Qiong-yin Wang for her critical English editing. Also, we would like to thank the funding of this research: National Natural Science Foundation of China (NSFC 81960086).

\section{Authors' contributions}

All authors fulfill the criteria for authorship. JY conceived and designed the research. JSC, PY acquired the data. JSC, CEL, NYL, TG drafted the manuscript and made critical revision of the manuscript for key intellectual content. All authors read and approved the final manuscript.

\section{Funding}

This study was supported by the National Natural Science Foundation of China (NSFC 81960086). The funding bodies did not play any roles in the design of the study and collection, analysis, and interpretation of data and in writing the manuscript.

\section{Availability of data and materials}

Since some patients did not allow us to publish their medical records, datasets generated and/or analyzed in the current study are not publicly available, but can be obtained from the correspondence author on reasonable request.

\section{Ethics approval and consent to participate}

All patients obtained written informed consent before participating in the study. The study was approved by the ethical committee of Second Hospital of Lanzhou University.

\section{Consent for publication}

Not applicable.
Received: 5 March 2020 Accepted: 20 July 2020

Published online: 29 July 2020

\section{References}

1. Marwick TH, Shah SJ, Thomas GD. Myocardial strain in the assessment of patients with heart failure: a review. JAMA Cardiol. 2019:4(3):287-94.

2. Normand C, Kaye DM, Povsic TJ, et al. Beyond pharmacological treatment: an insight into therapies that target specific aspects of heart failure pathophysiology. Lancet. 2019;393(10175):1045-55.

3. Mozaffarian D, Benjamin EJ, GO AS, et al. Heart disease and stroke statistics2015 update: a report from the American Heart Association. Circulation. 2015;131(4):e29-322

4. Cooper LB, Mentz RJ, Sun J, et al. Psychosocial factors, exercise adherence, and outcomes in heart failure patients. Circ Heart Fail. 2015;8(6):1044-51.

5. Mele D, Andrade A, Bettencourt $P$, et al. From Left Ventricular Ejection Fraction to Cardiac Hemodynamics: Role of Echocardiography in Evaluating Patients with Heart Failure. Heart Fail Rev. 2020;25(2):217-30.

6. Dabbah S, Reisner SA, Aronson D, et al. Left ventricular filling hemodynamics in patients with pulmonary edema and preserved versus reduced left ventricular ejection fraction: a prospective Doppler echocardiographic study. J Am Soc Echocardiogr. 2006;19(6):733-43.

7. Bosch L, Carluccio E, Coiro S, et al. Risk stratification of Asian patients with heart failure and reduced ejection fraction: the effectiveness of the Echo heart failure score. Eur J Heart Fail. 2017:19(12):1732-5.

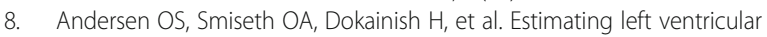
filling pressure by echocardiography. J Am Coll Cardiol. 2017:19(12):1732-5.

9. Ponikowski P, Voors AA, Anker SD, et al. 2016 ESC Guidelines for the diagnosis and treatment of acute and chronic heart failure: The Task Force for the diagnosis and treatment of acute and chronic heart failure of the European Society of Cardiology (ESC). Developed with the special contribution of the Heart Failure Association (HFA) of the ESC. Eur J Heart Fail. 2016;18(8):891-975.

10. Mitchell C, Rahko PS, Blauwet LA, et al. Guidelines for performing a comprehensive transthoracic echocardiographic examination in adults: recommendations from the American Society of Echocardiography. J Am Soc Echocardiogr. 2019;32(1):1-64.

11. Nishimura RA, Otto CM, Bonow RO, et al. 2017 AHA/ACC focused update of the 2014 AHA/ACC guideline for the Management of Patients with Valvular heart disease: a report of the American College of Cardiology/American Heart Association task force on clinical practice guidelines. J Am Coll Cardiol. 2017:70(2):252-89.

12. Yang $H$, Marwick TH, Wang $Y$, et al. Association between electrocardiographic and echocardiographic markers of stage $B$ heart failure and cardiovascular outcome. ESC Heart Fail. 2017:4(4):417-31.

13. Nagueh SF, Appleton CP, Gillebert TC, et al. Recommendations for the evaluation of left ventricular diastolic function by echocardiography. Eur J Echocardiogr. 2009;10(2):165-93.

14. Salah K, Stienen S, Pinto YM, et al. Prognosis and NT-proBNP in heart failure patients with preserved versus reduced ejection fraction. Heart. 2019; 105(15):1182-9.

15. Tanase MD, Radu S, Shurbaji SA, et al. Natriuretic peptides in heart failure with preserved left ventricular ejection fraction: from molecular evidences to clinical implications. Int J Mol Sci. 2019;20(11):2629.

16. Lai MY, Kan WC, Huang YT, et al. The Predictivity of N-terminal pro b-type natriuretic peptide for all-cause mortality in various follow-up periods among heart failure patients. J Clin Med. 2019;8(3):357.

17. Dong SJ. de las Fuentes $L$, Brown $A L$, et al. N-terminal pro B-type natriuretic peptide levels: correlation with echocardiographically determined left ventricular diastolic function in an ambulatory cohort. J Am Soc Echocardiogr. 2006;19(8):1017-25.

18. Chen YY, Yu XP, Chen SH. Clinical value of ultrasound index for evaluation of heart failure with mid-range ejection fraction. J Clin Cardiol. 2018;35(8): $726-30$

\section{Publisher's Note}

Springer Nature remains neutral with regard to jurisdictional claims in published maps and institutional affiliations.

\section{Competing interests}

The authors declare that they have no competing interests. 